\title{
Stereotactic body radiotherapy for de novo spinal metastases: systematic review
}

\author{
International Stereotactic Radiosurgery Society practice guidelines
}

\author{
Zain A. Husain, MD, ${ }^{1}$ Arjun Sahgal, MD, ${ }^{2}$ Antonio De Salles, MD, ${ }^{3}$ Melissa Funaro, MS, MLS, ${ }^{4}$ \\ Janis Glover, MLS, ${ }^{4}$ Motohiro Hayashi, ${ }^{5}$ Masahiro Hiraoka, MD, ${ }^{6}$ Marc Levivier, MD, ${ }^{7}$ Lijun Ma, \\ $\mathrm{PhD},{ }^{8}$ Roberto Martínez-Alvarez, MD, ${ }^{9} \mathrm{~J}$. lan Paddick, MSc, ${ }^{10}$ Jean Régis, MD, ${ }^{11}$ \\ Ben J. Slotman, MD, PhD,12 and Samuel Ryu, MD13
}

\begin{abstract}
'Department of Therapeutic Radiology, Yale School of Medicine, New Haven, Connecticut; ' 2 Department of Radiation Oncology, University of Toronto, Sunnybrook Odette Cancer Centre, Toronto, Ontario, Canada; ${ }^{3}$ Department of Neurosurgery, University of California, Los Angeles, California; ${ }^{4}$ Harvey Cushing/John Hay Whitney Medical Library, Yale University, New Haven, Connecticut; ${ }^{5}$ Department of Neurosurgery, Tokyo Women's Medical University, Tokyo; ${ }^{6}$ Department of Radiation Oncology, Kyoto University, Kyoto, Japan; ${ }^{7}$ Neurosurgery Service and Gamma Knife Center, Centre Hospitalier Universitaire Vaudois, Lausanne, Switzerland; ' Division of Physics, Department of Radiation Oncology, University of California, San Francisco, California; ' ${ }^{D}$ Department of Neurosurgery, Ruber International Hospital, Madrid, Spain; ${ }^{10}$ National Hospital for Neurology and Neurosurgery, London, United Kingdom; ${ }^{11}$ Department of Functional Neurosurgery, Timone University Hospital, Aix-Marseille University, Marseille, France; ${ }^{12}$ Department of Radiation Oncology, VU University Medical Center, Amsterdam, The Netherlands; and ${ }^{13}$ Department of Radiation Oncology, Stony Brook University, Stony Brook, New York
\end{abstract}

OBJECTIVE The aim of this systematic review was to provide an objective summary of the published literature pertaining to the use of stereotactic body radiation therapy (SBRT) specific to previously untreated spinal metastases.

METHODS The authors performed a systematic review, using Preferred Reporting Items for Systematic Reviews and Meta-Analyses (PRISMA) guidelines, of the literature found in a search of Medline, PubMed, Embase, and the Cochrane Library up to March 2015. The search strategy was limited to publications in the English language.

RESULTS A total of 14 full-text articles were included in the analysis. All studies were retrospective except for 2 studies, which were prospective. A total of 1024 treated spinal lesions were analyzed. The median follow-up time ranged from 9 to 49 months. A range of dose-fractionation schemes was used, the most common of which were 16-24 Gy/1 fraction (fx), $24 \mathrm{~Gy} / 2 \mathrm{fx}, 24-27 \mathrm{~Gy} / 3 \mathrm{fx}$, and 30-35 Gy/5 fx. In studies that reported crude results regarding in-field local tumor control, $346(85 \%)$ of 407 lesions remained controlled. For studies that reported actuarial values, the weighted average revealed a $90 \%$ 1-year local control rate. Only 3 studies reported data on complete pain response, and the weighted average of these results yielded a complete pain response rate of $54 \%$. The most common toxicity was new or progressing vertebral compression fracture, which was observed in $9.4 \%$ of cases; 2 cases $(0.2 \%)$ of neurologic injury were reported. CONCLUSION There is a paucity of prospective data specific to SBRT in patients with spinal metastases not otherwise irradiated. This systematic review found that SBRT is associated with favorable rates of local control (approximately $90 \%$ at 1 year) and complete pain response (approximately 50\%), and low rates of serious adverse events were found. Practice guidelines are summarized based on these data and International Stereotactic Radiosurgery Society consensus. https://thejns.org/doi/abs/10.3171/2017.1.SPINE16684

KEY WORDS stereotactic radiosurgery; SBRT; spinal metastases; systematic review; oncology

ABBREVIATIONS BED = biologically equivalent dose; CTV = clinical target volume; EBRT = external-beam radiation therapy; $f x=$ fraction(s); GTV = gross tumor volume; ISRS = International Stereotactic Radiosurgery Society; MDACC = MD Anderson Cancer Center; RCC = renal cell carcinoma; SBRT = stereotactic body radiation therapy. SUBMITTED June 25, 2016. ACCEPTED January 6, 2017.

INCLUDE WHEN CITING Published online June 9, 2017; DOI: 10.3171/2017.1.SPINE16684. 
$\mathrm{S}$ PINAL metastases are a common cause of morbidity in patients with cancer. Nearly 100,000 cases of bone metastases are diagnosed each year, and their most common location is the spine. ${ }^{12}$ Spinal metastases have traditionally been treated with conventional palliative irradiation. This approach is associated with several limitations, particularly relatively low rates of complete response to pain and local control. ${ }^{7,12,17,30}$ Furthermore, efficacy has been limited to the short term, and as patients are living longer with metastatic disease, more durable rates of pain relief are necessary. With respect to local control, actuarial rates after conventional palliative irradiation have been poorly studied. At least 1 study found 1-year local control rates of less than $50 \%$ in certain scenarios, such as in patients with bulky tumors with extraosseous extension. ${ }^{16}$ In addition, conventional low biologically equivalent dose (BED) irradiation, such as 8 Gy in 1 fraction (fx), has been associated with an increased rate of spinal adverse events, including malignant epidural spinal cord compression, hospitalization, and new/ worsened neurological symptoms. ${ }^{13}$ The data suggest that a suboptimal radiation dose might not be a good palliative treatment for patients with spinal metastases.

Stereotactic body radiation therapy (SBRT), with its delivery of a substantially higher BED than otherwise delivered conventionally, was developed with the intent to improve complete response rates to pain and local control. ${ }^{23}$ The current data seem to support this potential; however, the current literature is limited to data from a few prospective trials and predominantly retrospective studies. Furthermore, most of the literature is based on response in heterogeneous patient populations, including those with various tumor histologies, previous radiation, and/or surgical failures, as well as previously untreated patients. Given that previous irradiation affects the ability to deliver additional radiation to a given spinal level, to respect the cumulative dose tolerance to the spinal cord, reirradiation dose distributions are inherently more limited than in those treated with up-front (de novo) SBRT. This distinction is particularly critical when one considers that most local failures occur with progression in the epidural space.,22 Thus, the purpose of this study was to systematically review the literature for outcomes in patients with spinal metastases treated with SBRT in the "de novo" setting, that is, patients who have not had previous surgery or irradiation to the affected spinal segment.

\section{Methods}

A systematic review was performed using the Preferred Reporting Items for Systematic Reviews and Meta-Analyses (PRISMA) standards of quality for reporting systematic reviews with the assistance of a designated medical librarian team. ${ }^{14}$

\section{Search Strategy}

We conducted a systematic review by searching Medline (OvidSP 1946 through Week 1 of March 2015), PubMed (1946 to February 25, 2015), Embase (OvidSP 1974 through March 10, 2015), and the Cochrane Library (Wiley Online, inclusive years). The search strategy was not limited by study design but was limited to the Eng- lish language. Medline (OvidSP), Embase (OvidSP), and Cochrane searches were conducted on March 11, 2015. Supplementary efforts to identify studies included checking reference lists and contacting experts in the field.

Search words included spine/spinal neoplasms, spinal cord neoplasm, radiosurgery SBRT, stereotactic body radiotherapy, stereotactic radiosurgery, stereotactic body radiation, SABR, stereotactic ablative body radiation, stereotactic ablative body radiotherapy, radiotherapy dosage, fractures, compression, and radiation injuries.

\section{Eligibility Criteria}

Published studies that reported clinical outcomes for patients treated with SBRT for spinal metastases were included if the report included, at a minimum, clinical outcomes regarding local control or pain control. Studies that included a mixed group of previously irradiated and unirradiated patients were included only if outcomes regarding the previously unirradiated subset could be deciphered. Abstracts, case reports, studies with 5 or fewer patients, and reports not published in English were excluded. In cases of studies that were clearly updates of previous publications, the series with the longest follow-up was used.

\section{Outcome Measures}

The primary outcome measures were rates of local control and complete pain response. In addition, information on overall survival, numbers of patients and lesions, tumor histology, median follow-up duration, and dose and fractionation were also collected. Information was extracted directly from the published articles. For studies that reported crude results of local control, data were summarized by adding the total number of tumors with local control divided by the total number of treated lesions. For studies that reported actuarial results, the weighted average of the studies was used to generate an overall value. Similarly, for studies that reported complete pain response, a weighted average was used to generate an overall rate.

\section{Biologically Equivalent Dose}

To compare the efficacy of differing dose and fractionation schemes, the BED was calculated according to the equation $B E D=n d[1+d /(\alpha / \beta)]$, where $n$ is the number of fractions, $d$ is the dose per fraction, and the $\alpha / \beta$ ratio for tumor is 10 .

\section{Results \\ Search Results}

The initial search resulted in 348 results from OVID, 597 from Embase, 494 from PubMed, and 15 from the Cochrane database, which led to a total of 1454 results that then were assessed for removal of duplicates, leaving 932 results. These results, in turn, were screened based on title and abstract, which left 110 potential articles selected for in-depth screening. The full text of these articles was obtained, and ultimately, 14 articles were selected for inclusion. A Preferred Reporting Items for Systematic Reviews and Meta-Analyses flowchart with a list of reasons for exclusion is shown in Fig. 1. 


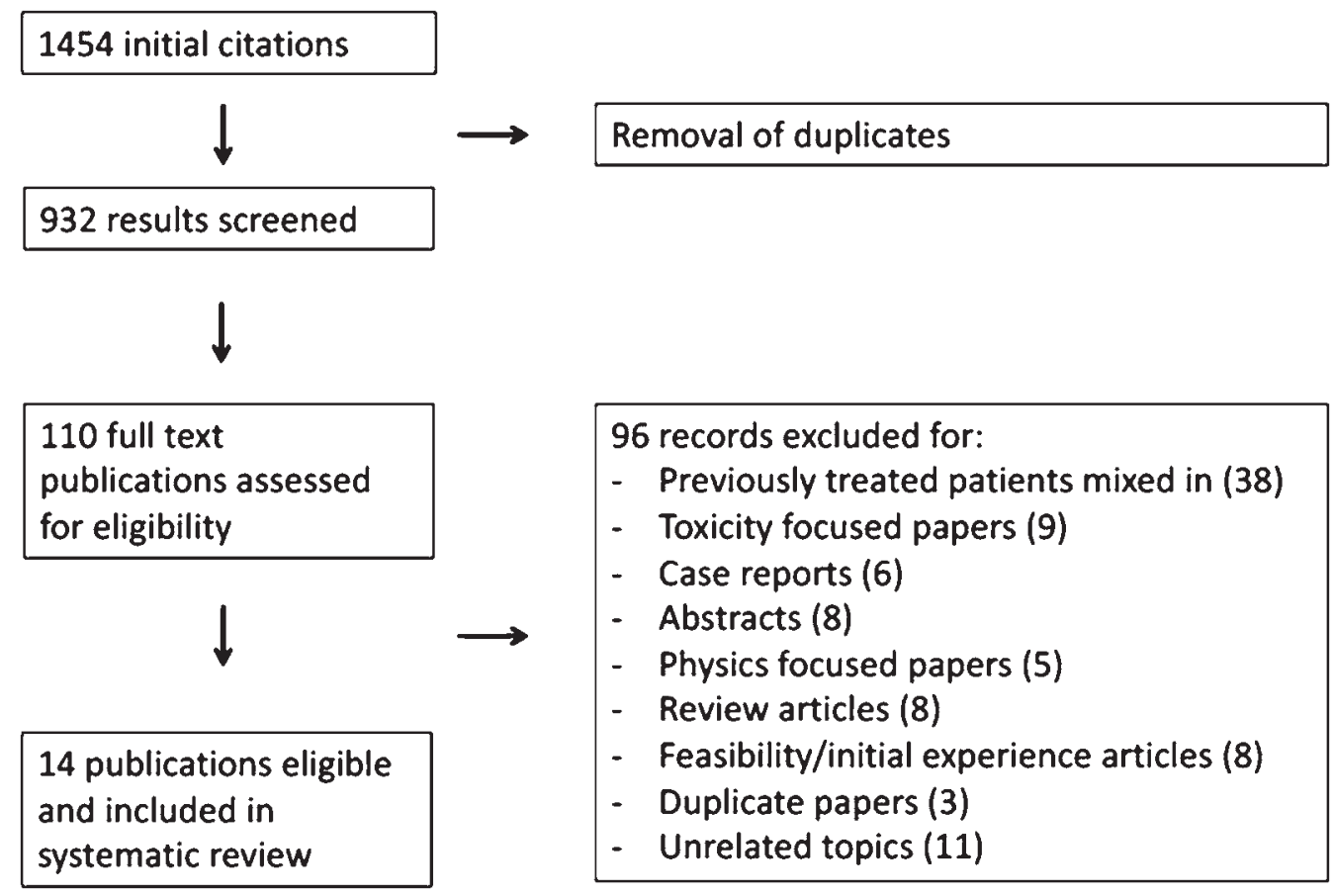

FIG. 1. Search strategy.

A total of 14 studies were found suitable for inclusion, and they all are listed in Table 1 along with other important findings from the studies. Nine studies included patients with mixed histologies, 4 included patients exclusively with renal cell carcinoma (RCC), and 1 included patients exclusively with breast cancer. Two studies were prospective in nature, and 12 were retrospective.

\section{Patient and Target Characteristics}

The total number of treated lesions was 1024 . The number of patients treated was estimated to be 816 . The reason this number is an estimation is that some studies reported only the number of patients or the number of lesions instead of both. For this reason, we assumed that each lesion described in the studies referred to a separate patient. The median follow-up durations ranged from 9 to 49 months.

\section{Notable Studies}

Only 2 prospective studies were found. The first was a Phase I/II study of SBRT from the MD Anderson Cancer Center (MDACC). ${ }^{2}$ It included previously irradiated patients, so data on only 28 patients without previous radiation or surgery were eligible for the analysis. Patients were treated with 27-30 Gy in 3-5 fx. The crude local control rate was $68.1 \%$. Pain response was not discussed.

The other prospective study was also from the MDACC and focused on previously unirradiated patients treated with single-fraction SBRT. ${ }^{8}$ This study included patients with various histologies and generally prescribed $18 \mathrm{~Gy}$ to the tumor; however, in cases of RCC, 24 Gy in a single fraction was delivered using a simultaneous integrated boost technique (24 Gy to gross tumor volume [GTV] in 1 patient and 18 Gy to clinical target volume [CTV] in 1 patient). Although none of the patients had undergone radia- tion previously, some patients had undergone previous surgical procedures; thus, inclusion was limited to 47 lesions in patients without previous surgery. The median followup duration for the entire group was 20 months. The median survival time for the entire group was 30 months, and survival times were similar in postoperative and de novo patients. Pain was assessed using the Brief Pain Inventory (BPI). ${ }^{16}$ The percentage of patients pain free was higher after treatment, and as a group, more of these patients had $\mathrm{a} \leq 3 \mathrm{BPI}$ score 3 and 6 months after treatment, although these results were not statistically significant.

The largest experience was a pooled multiinstitutional study focused specifically on previously untreated spinal metastases. ${ }^{11}$ It included data from 8 centers and involved 301 patients with 387 spinal metastases. The median dose was $24 \mathrm{~Gy}$ in $3 \mathrm{fx}$, although there was considerable variation in the fractionation scheme; approaches using 1-20 fx were used. With a median follow-up duration of 19.5 months, the local control rate was $89.9 \%$ at 1 year. There was a $4.1 \%$ risk of new vertebral compression fracture. Fifty-eight percent of the patients were rendered completely pain free.

\section{Radiation Dose}

We found considerable variations in dose and fractionation schemes among the reports and occasionally within individual studies, as detailed in Table 2. Overall, 8 studies used mainly a single-fraction approach, 1 study used mainly a 2-fx approach, and 5 studies used mainly a 3- to 5-fx approach. Common dose and fractionation schemes included 16-24 Gy/1 fx, 24 Gy/2 fx, 24-27 Gy/3 fx, and $30-35 \mathrm{~Gy} / 5 \mathrm{fx}$. The range of BEDs was $20-81.6 \mathrm{~Gy} ; 9$ of the 14 studies had a median BED of $50 \mathrm{~Gy}$ or higher. Table 3 lists commonly used fractionation schemes for SBRT and conventional irradiation. 
TABLE 1. Results from select series using spine SBRT for de novo treatment

\begin{tabular}{|c|c|c|c|c|c|c|c|c|}
\hline $\begin{array}{l}\text { Authors \& } \\
\quad \text { Year }\end{array}$ & $\begin{array}{l}\text { Tumors/ } \\
\text { Pts } \\
\text { Treated } \\
(\mathrm{n} / \mathrm{n})\end{array}$ & $\begin{array}{l}\text { Cancer } \\
\text { Type }\end{array}$ & $\begin{array}{l}\text { Follow-Up } \\
\text { Duration } \\
\text { Median } \\
\text { (mos) }\end{array}$ & $\begin{array}{c}\text { Local Control } \\
\text { Rate }(\%)\end{array}$ & $\begin{array}{l}\text { Complete Pain } \\
\text { Response (\%) }\end{array}$ & $\begin{array}{l}\text { Overall } \\
\text { Survival† }\end{array}$ & $\begin{array}{l}\text { Tumor Dose (Gy)/ } \\
\text { No. of Fx (range) }\end{array}$ & $\begin{array}{c}\text { BED } \\
(\alpha / \beta=10)(G y)\end{array}$ \\
\hline $\begin{array}{l}\text { Yamada et al., } \\
2008\end{array}$ & $103 / 93$ & Mixed & 15 (all pts) & $\begin{array}{l}93 \text { (96/103, } \\
\text { crude, } 2 \text { yrs) }\end{array}$ & NR & $\begin{array}{c}15 \text { mos (all pts, } \\
\text { median) }\end{array}$ & $18-24 / 1$ & 50.4-81.6 (range) \\
\hline $\begin{array}{l}\text { Sahgal et al., } \\
2009\end{array}$ & $18 / 14$ & Mixed & 9 & $\begin{array}{l}77.8(14 / 18 \\
\text { crude) }\end{array}$ & NR & NR & 24/3 (median) & 43.2 (median) \\
\hline $\begin{array}{l}\text { Sohn et al., } \\
\quad 2014\end{array}$ & $13 / 13$ & $\mathrm{RCC}$ & NR & 85.7 (1 yr) & 23.1 & 15 mos (median) & $38 / 4$ (mean) & 74.1 (mean) \\
\hline $\begin{array}{c}\text { Guckenberger } \\
\text { et al., } 2014\end{array}$ & $387 / 301$ & Mixed & 11.8 & $\begin{array}{c}90(1 \mathrm{yr}), 84 \\
(2 \mathrm{yrs})\end{array}$ & 58 & $\begin{array}{c}65 \% \text { (1 yr), } 44 \% \\
(2 \mathrm{yrs}) \text { (median } \\
19.5 \mathrm{mos})\end{array}$ & $\begin{array}{l}24 / 3 \text { (median) } \\
(10-60 / 1-20)\end{array}$ & $\begin{array}{c}43.2 \text { (median) (range } \\
20-78 \text { ) }\end{array}$ \\
\hline $\begin{array}{l}\text { Thibault et al., } \\
2014\end{array}$ & $51 / 51^{*}$ & $\mathrm{RCC}$ & 12.3 & 84.3 (crude) & NR & $64.1 \%(1 \mathrm{yr})$ & 24/2 (median) & 52.8 (median) \\
\hline $\begin{array}{l}\text { Sellin et al., } \\
\quad 2015\end{array}$ & $40 / 37$ & $\mathrm{RCC}$ & 49.0 & 57 & $\begin{array}{c}44.4 \text { (with improve- } \\
\text { ment) }\end{array}$ & $\begin{array}{l}16.3 \text { mos } \\
\text { (median) }\end{array}$ & 24/1 (median) & 81.6 (median) \\
\hline $\begin{array}{l}\text { Bate et al., } \\
\quad 2015\end{array}$ & $24 / 24^{*}$ & Mixed & 9.8 & $\begin{array}{l}95.8(1-y r \\
\text { crude) }\end{array}$ & NR & NR & $\begin{array}{c}22 / 1 \text { (median) } \\
(16-23 / 1)\end{array}$ & $\begin{array}{c}70.4 \text { (range } \\
41.6-75.9 \text { ) }\end{array}$ \\
\hline $\begin{array}{l}\text { Garg et al., } \\
2012\end{array}$ & $47 * / 47$ & Mixed & NR & 87.2 (crude) & NR & NR & $\begin{array}{c}18 \text { (GTV), } 16 \text { (CTV) } \\
\text { (non-RCC); } \\
24 \text { (GTV), } 18 \text { (CTV) } \\
\text { (RCC) }\end{array}$ & $\begin{array}{c}50.4 \text { (GTV), } 41.6 \\
\text { (CTV) (non-RCC); } \\
81.6 \text { (GTV), } 50.4 \\
\text { (CTV) (RCC) }\end{array}$ \\
\hline $\begin{array}{l}\text { Chang et al., } \\
2007\end{array}$ & $22 / 17$ & Mixed & NR & $\begin{array}{c}68.1(7 / 22 \\
\text { failures) }\end{array}$ & NR & NR & $27-30 / 3-5$ & 48-51.3 (range) \\
\hline $\begin{array}{l}\text { Chang et al., } \\
2012\end{array}$ & $131 / 93$ & Mixed & 23.7 & $\begin{array}{c}89.2(1-y r \\
\text { crude) }\end{array}$ & $\begin{array}{l}\text { NR; } 89.2 \text { (at } 1 \text { yr, } \\
\text { "pain control") }\end{array}$ & $19 \mathrm{mos}$ & $\begin{array}{c}19.9 / 1 \text { (mean } \\
\text { equivalent) }\end{array}$ & 59.5 (mean) \\
\hline $\begin{array}{l}\text { Gerszten et } \\
\text { al., } 2005\end{array}$ & $8 / 8^{*}$ & Breast & 16 & 100 & NR & NR & $\begin{array}{l}12.5-22.5 \text { (mean } \\
19 \mathrm{~Gy})\end{array}$ & $\begin{array}{c}\text { 28.13-73.13 (range) } \\
\quad \text { (mean 55.1) }\end{array}$ \\
\hline Gill et al., 2012 & $14^{*} / 14$ & Mixed & 34 & 85.7 & NR & $\begin{array}{c}80 \%(1 \mathrm{yr}), 57 \% \\
(2 \mathrm{yr}) \text { (all) }\end{array}$ & $30-35 / 5$ & 48-59.5 (range) \\
\hline $\begin{array}{l}\text { Ryu et al., } \\
2004\end{array}$ & $61 / 49$ & Mixed & $\begin{array}{l}\mathrm{NR}(\max \\
24)\end{array}$ & NR & $\begin{array}{c}\text { NR (85 complete \& } \\
\text { partial) }\end{array}$ & $\begin{array}{c}74.3 \%(1 \mathrm{yr} \\
\text { actuarial) }\end{array}$ & $10-16 / 1$ & 20-41.6 (range) \\
\hline $\begin{array}{l}\text { Staehler et al., } \\
2011\end{array}$ & $105 / 55$ & $\mathrm{RCC}$ & 33.4 & 90.4 at $2 \mathrm{yrs}$ & $\begin{array}{l}0 \text { (median) on visual } \\
\text { analogue scale }\end{array}$ & $\begin{array}{l}17.4 \text { mos (me- } \\
\text { dian) }\end{array}$ & 20/1 (median) & 60 (median) \\
\hline
\end{tabular}

$\mathrm{NR}=$ not reported; $\mathrm{pts}=$ patients.

* Number of patients or treated lesions was not explicitly stated, so an estimate was created using an assumption of 1 lesion per patient.

† Overall survival was reported for all patients, not necessarily only the de novo subset.

\section{Local Tumor Control}

Data on local control were available for all studies except for 1 of them. All studies for which local control data were reported used follow-up imaging as the basis for reporting outcomes. One study, however, also used symptomatic findings of worsened pain as a marker of progression. ${ }^{20}$ Reporting of local control differed; some studies reported crude rates, and others reported actuarial rates. For studies that reported crude values, $346(85 \%)$ of 407 lesions remained controlled. For studies that reported actuarial values, the weighted average result revealed a $90 \%$ 1-year local control rate.

\section{Pain Response}

Only 6 studies reported any data on pain response specifically for de novo patients, and it was reported most commonly using a visual analog scale. One study used a descriptive scale (i.e., pain free, mild/moderate pain, and severe pain). Three studies reported a complete pain response rate that ranged from $23.1 \%$ to $58 \%$. The weighted average of these results revealed a complete pain response rate of 54\%. No study documented pain-control results using the international consensus pain response end points.

\section{Late Toxicity}

Eleven of the 14 studies provided data regarding late toxicity (Table 2). The most common toxicity was new or progressive vertebral compression fracture, which occurred in $9.4 \%$ of the patients overall. Most studies grouped new fractures and progression of existing fractures together. Two studies reported that the rate of new vertebral compression fracture after SBRT was 43\% and that the rate of progression of existing vertebral compression fractures was 57\%.11,28 Time to fracture was reported 
TABLE 2. Rates of late toxicity reported in patients undergoing spine SBRT

\begin{tabular}{|c|c|c|}
\hline Authors \& Year & $\begin{array}{l}\text { Tumors/ } \\
\text { Pts } \\
\text { Treated } \\
(\mathrm{n} / \mathrm{n})\end{array}$ & Late Toxicity \\
\hline $\begin{array}{l}\text { Yamada et al., } \\
2008\end{array}$ & $103 / 93$ & $\begin{array}{l}2 \text { VCFs }(1.94 \%), 1 \text { tracheoesophageal } \\
\text { fistula (1\%), } 0 \text { myelopathy }\end{array}$ \\
\hline $\begin{array}{l}\text { Sahgal et al., } \\
\quad 2009\end{array}$ & $18 / 14$ & No myelopathy, no grade $\geq 3$ late toxicity \\
\hline Sohn et al., 2014 & $13 / 13$ & 2 VCFs $(15.4 \%)$ \\
\hline $\begin{array}{l}\text { Guckenberger et } \\
\text { al., } 2014\end{array}$ & $387 / 301$ & $\begin{array}{l}30 \text { new or worsened VCFs (7.8\%), no } \\
\text { myelopathy }\end{array}$ \\
\hline $\begin{array}{l}\text { Thibault et al., } \\
2014\end{array}$ & 51/NR & $\begin{array}{l}\text { No myelitis, } 10 \text { new or worsened VCFs } \\
\quad(19.6 \%)\end{array}$ \\
\hline $\begin{array}{l}\text { Sellin et al., } \\
\quad 2015\end{array}$ & $40 / 37$ & $\begin{array}{l}\text { NA (no comment on late neurologic tox- } \\
\text { icity; did not separate progression-re- } \\
\text { lated from radiation-related fractures) }\end{array}$ \\
\hline Bate et al., 2015 & 24/NR & 5 VCFs (21\%), no myelopathy \\
\hline Garg et al., 2012 & $\mathrm{NR} / 47$ & 2 cases of neurologic injury, 13 VCFs* \\
\hline $\begin{array}{l}\text { Chang et al., } \\
2007\end{array}$ & $22 / 17$ & No myelopathy \\
\hline $\begin{array}{l}\text { Chang et al., } \\
2012\end{array}$ & $131 / 93$ & $\begin{array}{l}\text { No myelopathy, } 12 \text { symptomatic VCFs } \\
(9.2 \%)\end{array}$ \\
\hline $\begin{array}{l}\text { Gerszten et al., } \\
2005\end{array}$ & $8 / N R$ & NA \\
\hline Gill et al., 2012 & $\mathrm{NR} / 14$ & $\begin{array}{l}\text { No skin, musculoskeletal, or neurologic } \\
\text { toxicities }\end{array}$ \\
\hline Ryu et al., 2004 & $61 / 49$ & NA \\
\hline $\begin{array}{l}\text { Staehler et al., } \\
2011\end{array}$ & $105 / 55$ & No late complications \\
\hline
\end{tabular}

$\mathrm{NA}=$ not available; $\mathrm{VCF}=$ vertebral compression fracture.

* It is unclear if these VCFs occurred in the patients undergoing surgery or radiation; however, given the assumption that surgery would stabilize disease and make fracture less likely, it was assumed that they were in the radiationonly cohort.

in only 1 study and was found to be 1.6 months. ${ }^{28}$ Overall, only $2(0.2 \%)$ cases of neurologic injury were reported. A single tracheoesophageal fistula in a patient who underwent adriamycin chemotherapy was reported.

\section{Survival}

All studies reported overall survival data including all patients but not specifically patients with previously untreated spinal metastases, who were the focus of this study. The median overall survival results were favorable, ranging from 15 to 19 months, and the 1-year overall survival rates ranged from $65 \%$ to $80 \%$.

\section{Discussion}

In this systematic review, we synthesized results from 14 studies, including more than 1000 lesions treated with SBRT for de novo spinal metastasis. The results support the use of spine SBRT in this population, due to the high rate of local control achieved, with a 1-year actuarial rate
TABLE 3. Common dose and fractionation regimens used in SBRT and conventional irradiation

\begin{tabular}{ccccc}
\hline Total Dose (Gy) & Dose/Fx (Gy) & BED (Gy) & No. of Fx & Technique \\
\hline 24 & 24 & 81.6 & 1 & SBRT \\
\hline 24 & 12 & 52.8 & 2 & SBRT \\
\hline 27 & 9 & 51.3 & 3 & SBRT \\
\hline 18 & 18 & 50.4 & 1 & SBRT \\
\hline 30 & 6 & 48.0 & 5 & SBRT \\
\hline 24 & 8 & 43.2 & 3 & SBRT \\
\hline 30 & 3 & 39 & 10 & EBRT \\
\hline 20 & 4 & 28 & 5 & EBRT \\
\hline 8 & 8 & 14.4 & 1 & EBRT \\
\hline
\end{tabular}

of $90 \%$. In terms of pain response, data were available from only half of the studies included in this search. Three study reports included results on complete pain response. Moreover, although the rates of complete pain response were favorable, with a $54 \%$ weighted rate, no study used international consensus pain response end points to account for possible changes in medication use, which might have obfuscated the true source of the benefit. Nevertheless, the $54 \%$ rate of complete relief is substantially higher than the $23 \%$ reported in a previous systematic review of conventional external-beam radiation therapy (EBRT). ${ }^{5}$ Late toxicity was low, with a $9 \%$ rate of overall vertebral compression fracture, a $0.2 \%$ crude risk of neurologic injury, and 1 case of tracheoesophageal fistula.

Our study is also notable in that the results highlight the wide variety of dose and fractionation schemes currently being used for spine SBRT. As seen in Table 3, regardless of the fractionation scheme chosen, SBRT resulted in doses that are significantly greater than those achieved with conventional irradiation. To date, there is no Level I evidence to suggest a benefit of 1 SBRT dose fractionation over another. However, the results of some institutional series suggest a benefit to higher-dose single-fraction approaches. ${ }^{6}$ High-dose single-fraction approaches have also been associated with an increased risk of vertebral compression fracture. ${ }^{21}$ A randomized study to compare $24 \mathrm{~Gy}$ in $1 \mathrm{fx}$ versus $27 \mathrm{~Gy}$ in $3 \mathrm{fx}$ is nearly finished accruing patients (ClinicalTrials.gov Identifier NCT01223248), and the hope is that it will provide answers on the subject.

Emerging data, at least from the conventional EBRT setting, suggest that higher doses might be more effective. A recent review of 299 patients with uncomplicated spinal metastases (no previous radiation, surgery, or cord compression) compared outcomes of patients treated with conventional EBRT using single-fraction regimens of 8 Gy or longer course regimens (most commonly, $20 \mathrm{~Gy} / 5$ fx or $30 \mathrm{~Gy} / 10 \mathrm{fx}) .{ }^{13}$ Investigators studied the rates of spinal adverse events, namely, symptomatic vertebral body fracture, hospitalization for uncontrolled pain at the previously treated spine site, interventional procedures for pain at the treated site, salvage spinal surgery, new or worsened neurological symptoms, and cord or cauda equina compression. In a propensity score-matched analysis, the rates of spinal adverse events were $22 \%$ in the single-fraction arm and $6 \%$ in the multifraction arm $(p=0.003)$. In mul- 
TABLE 4. ISRS-recommended patient selection for consideration of spine SBRT outside a clinical trial*

\begin{tabular}{|c|c|c|}
\hline Criteria & Rationale & $\begin{array}{l}\text { Level of } \\
\text { Evidence }\end{array}$ \\
\hline \multicolumn{3}{|l|}{ Inclusion } \\
\hline Oligometastasis involving the spine & $\begin{array}{l}\text { These pts generally have a long expected survival \& thus are most likely to benefit } \\
\text { from radiosurgery/SBRT }\end{array}$ & V \\
\hline $\begin{array}{l}\text { Pts w/ radioresistant histology (RCC, melanoma, } \\
\text { sarcoma) }\end{array}$ & Higher doses of radiation might be associated w/ improved local tumor control & IV/V \\
\hline $\begin{array}{l}\text { Patients with paraspinal extension contiguous to } \\
\text { the spine }\end{array}$ & $\begin{array}{l}\text { Pts w/ extraosseous extension might experience improved soft-tissue tumor } \\
\text { control }\end{array}$ & IV \\
\hline \multicolumn{3}{|l|}{ Exclusion } \\
\hline Pts $w /$ an expected survival time of $<3$ mos & Pts w/ a shorter expected survival time are less likely to benefit from SBRT & V \\
\hline Mechanically unstable based on the SINS score & $\begin{array}{l}\text { Pts } w / \text { mechanical instability should be treated w/ surgical stabilization before } \\
\text { radiotherapy }\end{array}$ & IV/V \\
\hline$>3$ sites to be treated in a single session & $\begin{array}{l}\text { For logistical reasons, it is difficult to keep a pt adequately immobilized for long } \\
\text { enough to accurately treat more than } 3 \text { lesions in a single session }\end{array}$ & V \\
\hline $\begin{array}{l}\text { Spinal cord compression or cauda equina syn- } \\
\text { drome }\end{array}$ & These pts should be preferentially treated w/ up-front decompressive surgery $\dagger$ & I \\
\hline
\end{tabular}

SINS = spinal instability neoplastic score.

* Note that these are suggestions, and patients need not meet all criteria to be considered candidates for treatment.

$\dagger$ Based on the results of Patchell et al. ${ }^{17}$

tivariate analysis, single-fraction irradiation, a spinal instability neoplastic score of 11 or higher, and higher body mass index predicted adverse events, which leads us to prefer higher total dose-fractionated approaches when using conventional EBRT for spine metastases.

The question of whether higher-dose irradiation with SBRT can yield improvements over conventional EBRT is under investigation in the Radiation Therapy Oncology Group (RTOG) 0631 trial (ClinicalTrials.gov Identifier NCT00922974), a Phase II/III study to compare 8 Gy in 1 fx and 16-18 Gy of SBRT. The Phase II feasibility component has been completed, and the Phase III portion is currently under way. ${ }^{18}$ This study will be limited to de novo patients and will focus on pain response at 3 months; it should provide high-level evidence for the benefits of high-dose SBRT in comparison with those of conventional palliative irradiation. In addition, a randomized Phase II study from the National Cancer Institute of Canada (ClinicalTrials.gov Identifier NCT02512965) is comparing outcomes between $20 \mathrm{~Gy}$ in $5 \mathrm{fx}$ of conventional palliative irradiation with 24 Gy in $2 \mathrm{fx}$ of SBRT. At the time we wrote this review, 20 of the planned 54 patients had been enrolled.

Another notable finding of this systematic review is the favorable median survival time observed (15-17 months). Although this result likely represents patient selection, it also highlights the limitations of previous trials that focused on pain outcomes at short intervals of 3 months. It also suggests that pain and disease control 6 months to even 1 year later might be more reasonable end points on which to focus in future trials. Survival-prediction models reported by both the Cleveland Clinic and MDACC might identify longer-term survivors, but their results remain to be validated on a larger scale. ${ }^{4,27}$

Given the absence of randomized data, the question of who the optimal candidate is for spine SBRT is challenging. Patients ideally would be treated in a clinical trial.
In the absence of clinical trial availability, decisions are made for SBRT on a case-by-case basis, geared around 2 concepts, 1) patient longevity and the importance of durable local control and 2) markers of local disease aggressiveness that suggest potential inferior outcomes with conventional EBRT. In the first case, markers of patient longevity, such as bone-only metastases or oligometastatic disease $^{28}$ or application of the aforementioned survival models, can be helpful tools in patient selection. In terms of local disease aggressiveness, the excellent outcomes seen with SBRT in traditionally radioresistant tumors, such as melanoma, RCC, and sarcoma, suggest its potential utility in patients. For example, the largest RCC study (which included 105 lesions) found a 2-year local control rate of $90 \%{ }^{26}$ In addition, previous studies with conventional EBRT found that patients with bulky "mass-type" tumors with extraosseous extension experienced a less than $50 \%$ control rate at 1 year when conventional EBRT was used. ${ }^{15}$ It is thought that the higher doses achieved with SBRT might help overcome these poor control rates. Table 4 lists International Stereotactic Radiosurgery Society (ISRS) recommendations for patients in the de novo setting for whom spine SBRT should be considered.

Our study had limitations, largely because of the lack of high-quality studies focused on de novo spine metastases. In addition, authors of most of the published literature analyzed a mixed patient population, including those with recurrent or progressive spine metastases along with radiation-naive spinal lesions. Frequently, results were not reported separately for the previously untreated group; thus, the data were not sufficient for inclusion in our study. Given that spine SBRT is a technically demanding procedure, most publications on the subject emanated from the same few institutions. Although attempts were made to avoid duplication of data when a publication was a clear update of a previous series, in other instances in which 
the possibility of duplication was unclear or unknown, the studies were included. Last, significant variability existed between studies in regard to pain assessment, definitions of local tumor control, and the timing of follow-up imaging studies. It is fortunate that attempts to standardize these procedures are under way, and guidelines were published recently. ${ }^{29}$ In addition, it should be noted that the authors of most papers that described outcomes for spine SBRT did not take into account factors such as the type and amount of systemic therapy patients received, which certainly could have had an effect on factors such as overall survival and local tumor control.

\section{Conclusions}

In summary, results of this review confirm high rates of local control (90\% at 1 year) and complete pain response $(>50 \%)$ and low rates of toxicity for patients with de novo spinal metastases after SBRT. However, the quality of published studies currently is limited. Additional prospective (and preferably histology-specific) study of de novo patients is needed. The 2 randomized studies currently under way should provide high-level evidence to better elucidate the relative benefits from and outcomes of spine SBRT in the near future.

Given the paucity of prospective data, the ISRS recommendation is to participate preferentially in clinical trials if they are available. If no trial is available, then based on the literature and current clinical trial inclusion and exclusion criteria, the following are reasonable criteria for offering patients spine SBRT: oligometastatic disease, boneonly metastases and an expected survival of $>3$ months, bulky tumors with extraosseous extension, tumors with low-grade epidural disease, radioresistant histology (RCC, melanoma, or sarcoma), and limited disease to be treated (no more than 3 separate spinal sites, each with no more than 2 contiguous vertebral bodies that require treatment); patients who are mechanically unstable and those who have symptomatic malignant epidural spinal cord compression or cauda equina syndrome should be excluded. It should be noted that these recommendations are based mainly on expert opinion corresponding to low-level evidence (Levels IV-V), as summarized in Table 4.

\section{References}

1. Bate BG, Khan NR, Kimball BY, Gabrick K, Weaver J: Stereotactic radiosurgery for spinal metastases with or without separation surgery. J Neurosurg Spine 22:409-415, 2015

2. Chang EL, Shiu AS, Mendel E, Mathews LA, Mahajan A, Allen PK, et al: Phase I/II study of stereotactic body radiotherapy for spinal metastasis and its pattern of failure. J Neurosurg Spine 7:151-160, 2007

3. Chang UK, Cho WI, Kim MS, Cho CK, Lee DH, Rhee CH: Local tumor control after retreatment of spinal metastasis using stereotactic body radiotherapy; comparison with initial treatment group. Acta Oncol 51:589-595, 2012

4. Chao ST, Koyfman SA, Woody N, Angelov L, Soeder SL, Reddy CA, et al: Recursive partitioning analysis index is predictive for overall survival in patients undergoing spine stereotactic body radiation therapy for spinal metastases. Int J Radiat Oncol Biol Phys 82:1738-1743, 2012

5. Chow E, Harris K, Fan G, Tsao M, Sze WM: Palliative ra- diotherapy trials for bone metastases: a systematic review. J Clin Oncol 25:1423-1436, 2007

6. Folkert MR, Bilsky MH, Tom AK, Oh JH, Alektiar KM, Laufer I, et al: Outcomes and toxicity for hypofractionated and single-fraction image-guided stereotactic radiosurgery for sarcomas metastasizing to the spine. Int J Radiat Oncol Biol Phys 88:1085-1091, 2014

7. Foro Arnalot P, Fontanals AV, Galcerán JC, Lynd F, Latiesas XS, de Dios NR, et al: Randomized clinical trial with two palliative radiotherapy regimens in painful bone metastases: $30 \mathrm{~Gy}$ in 10 fractions compared with $8 \mathrm{~Gy}$ in single fraction. Radiother Oncol 89:150-155, 2008

8. Garg AK, Shiu AS, Yang J, Wang XS, Allen P, Brown BW, et al: Phase $1 / 2$ trial of single-session stereotactic body radiotherapy for previously unirradiated spinal metastases. Cancer 118:5069-5077, 2012

9. Gerszten PC, Burton SA, Welch WC, Brufsky AM, Lembersky BC, Ozhasoglu C, et al: Single-fraction radiosurgery for the treatment of spinal breast metastases. Cancer 104:22442254,2005

10. Gill B, Oermann E, Ju A, Suy S, Yu X, Rabin J, et al: Fiducial-free CyberKnife stereotactic body radiation therapy (SBRT) for single vertebral body metastases: acceptable local control and normal tissue tolerance with 5 fraction approach. Front Oncol 2:39, 2012

11. Guckenberger M, Mantel F, Gerszten PC, Flickinger JC, Sahgal A, Létourneau D, et al: Safety and efficacy of stereotactic body radiotherapy as primary treatment for vertebral metastases: a multi-institutional analysis. Radiat Oncol 9:226, 2014

12. Hartsell WF, Scott CB, Bruner DW, Scarantino CW, Ivker RA, Roach M III, et al: Randomized trial of short- versus long-course radiotherapy for palliation of painful bone metastases. J Natl Cancer Inst 97:798-804, 2005

13. Lam TC, Uno H, Krishnan M, Lutz S, Groff M, Cheney M, et al: Adverse outcomes after palliative radiation therapy for uncomplicated spine metastases: role of spinal instability and single-fraction radiation therapy. Int J Radiat Oncol Biol Phys 93:373-381, 2015

14. Liberati A, Altman DG, Tetzlaff J, Mulrow C, Gøtzsche PC, Ioannidis JP, et al: The PRISMA statement for reporting systematic reviews and meta-analyses of studies that evaluate health care interventions: explanation and elaboration. PLoS Med 6:e1000100, 2009

15. Mizumoto M, Harada H, Asakura H, Hashimoto T, Furutani $\mathrm{K}$, Hashii $\mathrm{H}$, et al: Radiotherapy for patients with metastases to the spinal column: a review of 603 patients at Shizuoka Cancer Center Hospital. Int J Radiat Oncol Biol Phys 79:208-213, 2011

16. Nguyen J, Chow E, Zeng L, Zhang L, Culleton S, Holden $\mathrm{L}$, et al: Palliative response and functional interference outcomes using the Brief Pain Inventory for spinal bony metastases treated with conventional radiotherapy. Clin Oncol (R Coll Radiol) 23:485-491, 2011

17. Patchell RA, Tibbs PA, Regine WF, Payne R, Saris S, Kryscio RJ, et al: Direct decompressive surgical resection in the treatment of spinal cord compression caused by metastatic cancer: a randomised trial. Lancet 366:643-648, 2005

18. Ryu S, Pugh SL, Gerszten PC, Yin FF, Timmerman RD, Hitchcock YJ, et al: RTOG 0631 phase 2/3 study of image guided stereotactic radiosurgery for localized (1-3) spine metastases: phase 2 results. Pract Radiat Oncol 4:76-81, 2014

19. Ryu S, Rock J, Rosenblum M, Kim JH: Patterns of failure after single-dose radiosurgery for spinal metastasis. J Neurosurg 101 (Suppl 3):402-405, 2004

20. Sahgal A, Ames C, Chou D, Ma L, Huang K, Xu W, et al: Stereotactic body radiotherapy is effective salvage therapy 
for patients with prior radiation of spinal metastases. Int $\mathbf{J}$ Radiat Oncol Biol Phys 74:723-731, 2009

21. Sahgal A, Atenafu EG, Chao S, Al-Omair A, Boehling N, Balagamwala EH, et al: Vertebral compression fracture after spine stereotactic body radiotherapy: a multi-institutional analysis with a focus on radiation dose and the spinal instability neoplastic score. J Clin Oncol 31:3426-3431, 2013

22. Sahgal A, Bilsky M, Chang EL, Ma L, Yamada Y, Rhines $\mathrm{LD}$, et al: Stereotactic body radiotherapy for spinal metastases: current status, with a focus on its application in the postoperative patient. J Neurosurg Spine 14:151-166, 2011

23. Sahgal A, Roberge D, Schellenberg D, Purdie TG, Swaminath A, Pantarotto J, et al: The Canadian Association of Radiation Oncology scope of practice guidelines for lung, liver and spine stereotactic body radiotherapy. Clin Oncol (R Coll Radiol) 24:629-639, 2012

24. Sellin JN, Reichardt W, Bishop AJ, Suki D, Rhines LD, Settle SH, et al: Factors affecting survival in 37 consecutive patients undergoing de novo stereotactic radiosurgery for contiguous sites of vertebral body metastasis from renal cell carcinoma. J Neurosurg Spine 22:52-59, 2015

25. Sohn S, Chung CK, Sohn MJ, Chang UK, Kim SH, Kim J, et al: Stereotactic radiosurgery compared with external radiation therapy as a primary treatment in spine metastasis from renal cell carcinoma: a multicenter, matched-pair study. J Neurooncol 119:121-128, 2014

26. Staehler M, Haseke N, Nuhn P, Tüllmann C, Karl A, Siebels $\mathrm{M}$, et al: Simultaneous anti-angiogenic therapy and singlefraction radiosurgery in clinically relevant metastases from renal cell carcinoma. BJU Int 108:673-678, 2011

27. Tang C, Hess K, Bishop AJ, Pan HY, Christensen EN, Yang $\mathrm{JN}$, et al: Creation of a prognostic index for spine metastasis to stratify survival in patients treated with spinal stereotactic radiosurgery: secondary analysis of mature prospective trials. Int J Radiat Oncol Biol Phys 93:118-125, 2015

28. Thibault I, Al-Omair A, Masucci GL, Masson-Côté L, Lochray $\mathrm{F}, \mathrm{Korol} \mathrm{R}$, et al: Spine stereotactic body radiotherapy for renal cell cancer spinal metastases: analysis of outcomes and risk of vertebral compression fracture. J Neurosurg Spine 21:711-718, 2014

29. Thibault I, Chang EL, Sheehan J, Ahluwalia MS, Guckenberger M, Sohn MJ, et al: Response assessment after stereotactic body radiotherapy for spinal metastasis: a report from the SPIne response assessment in Neuro-Oncology (SPINO) group. Lancet Oncol 16:e595-e603, 2015

30. van der Linden YM, Lok JJ, Steenland E, Martijn H, van Houwelingen H, Marijnen CA, et al: Single fraction radiotherapy is efficacious: a further analysis of the Dutch Bone Metastasis Study controlling for the influence of retreatment. Int J Radiat Oncol Biol Phys 59:528-537, 2004
31. Yamada Y, Bilsky MH, Lovelock DM, Venkatraman ES, Toner S, Johnson J, et al: High-dose, single-fraction imageguided intensity-modulated radiotherapy for metastatic spinal lesions. Int J Radiat Oncol Biol Phys 71:484-490, 2008

\section{Disclaimer}

These guidelines should not be considered inclusive of all methods of care or exclusive of other methods of care reasonably directed to obtain similar results. Physicians must make the ultimate judgment on the basis of characteristics and circumstances of each individual patient. Adherence to this guideline will not ensure successful treatment in every situation. The authors of this guideline and the International Stereotactic Radiosurgery Society assume no liability for the information, conclusions, or recommendations contained in this report.

\section{Disclosures}

Dr. Husain received support for non-study-related clinical or research efforts overseen by Merck; Dr. Paddick has served as a consultant for Elekta Instrument AB; Dr. Régis has served as a consultant for Medtronic and Elekta AB. Dr. Sahgal has received research grants from Elekta $\mathrm{AB}$, Medtronic, and Varian; received travel accommodations/expenses paid by Medtronic, Elekta AB, and Varian; attended past educational seminars held by Medtronic, Elekta AB, and Varian Medical Systems; and has acted in a consulting/advisory role for Varian Medical Systems and Hoffmann-LaRoche. The other authors report no conflict of interest concerning the materials or methods used in this study or the findings specified in this paper.

\section{Author Contributions}

Conception and design: Husain, Sahgal, Ryu. Acquisition of data: Husain, Funaro, Glover. Analysis and interpretation of data: Husain, Sahgal, Ryu. Drafting the article: Husain, Sahgal. Critically revising the article: Husain, Sahgal, De Salles, Hayashi, Hiraoka, Levivier, Ma, Martínez-Alvarez, Paddick, Régis, Slotman, Ryu. Reviewed submitted version of manuscript: Husain, Sahgal, De Salles, Hayashi, Hiraoka, Levivier, Ma, MartínezAlvarez, Paddick, Régis, Slotman, Ryu. Approved the final version of the manuscript on behalf of all authors: Husain. Study supervision: Husain, Sahgal, Ryu.

\section{Correspondence}

Zain A. Husain, Department of Therapeutic Radiology, Yale University, 333 Cedar St., New Haven, CT 06510. email: zain. husain@yale.edu. 